УДК 81

DOI 10.52575/2712-7451-2021-40-2-191-197

\title{
Интерпретация императивной ситуации в дискурсе социальной рекламы
}

\author{
Шлык Е.В. \\ Брянский государственный университет имени академика И.Г. Петровского, \\ Россия, 241036, г. Брянск, ул. Бежицкая, д. 14 \\ E-mail: shlykl@mail.ru
}

\begin{abstract}
Аннотация. Работа посвящена анализу текстов социальной рекламы на русском языке с привлечением соответствующих данных англо- и немецкоязычных текстов. Представлен анализ средств выражения прямой и косвенной императивности. Особый интерес вызывает последняя, поскольку дискурс общественной рекламы реже предполагает прямой императив в отличие от коммерческой, чаще императивный смысл лишь имплицируется, заставляя реципиента размышлять, давая предпосылки для самостоятельных выводов, оценки, построения ассоциативного ряда. Являясь фрагментом категории модальности, побудительность представляет различные оттенки модальных значений, находящих выражение в дискурсе социальной рекламы.
\end{abstract}

Ключевые слова: императивная ситуация, социальная реклама, имплицитность, эксплицитность, категориальная императивность, некатегориальная императивность.

Для цитирования: Шлык Е.В. 2021. Интерпретация императивной ситуации в дискурсе социальной рекламы. Вопросы журналистики, педагогики, языкознания, 40 (2): 191-197. DOI: $10.52575 / 2712-7451-2021-40-2-191-197$

\section{Interpretation of the Imperative Situation in Public Service advertising discourse}

\author{
Elena V. Shlyk \\ I.G. Petrovski Bryansk State Academition University, \\ 14 Beshitskaya St, Bryansk, 241036, Russia \\ E-mail: shlykl@mail.ru
}

\begin{abstract}
The article represents the results of the public service advertising texts analysis in Russian with the use of relevant English and German-language texts. The discourse of public advertising less often assumes a direct imperative in contrast to commercial, more often the imperative meaning is only implicated, forcing the recipient to think, presenting prerequisites for independent conclusions, evaluation, building an associative series. As a fragment of the modality category, motivation represents various connotations of modal meanings in the discourse of social advertising. An imperative situation, being a special type of modality, can be directly an act of will expression. The categorical imperative semantics is represented in the relevant imperative forms. The implicit variety of non-categorical imperative is presented with the help of a future indicative, questions about the realization of a possibility, forms of the subjunctive mood that represent the modality of a possibility, modal verbs of different semantics, forms of the infinitive. Additional connotations of meanings are revealed, due to the presence in one or another language of unique forms that do not have an equivalent in another language.
\end{abstract}

Keywords: imperative situation, public service advertising, implicitness, explicitness, categorical imperative, non-categorical imperative.

For citation: Shlyk E.V. 2021. Interpretation of the Imperative Situation in Public Service advertising discourse. Issues in Journalism, Education, Linguistics, 40 (2): 191-197 (in Russian). DOI: $10.52575 / 2712-7451-2021-40-2-191-197$ 


\section{Введение}

Проблема интерпретации императивной ситуации в дискурсе социальной рекламы приобретает всё большую актуальность в связи с увеличением объема общественно значимой рекламы в современном мире. Термин «социальная реклама» переводится с английского как public service advertising или public advertising и определяется как общественная или некоммерческая реклама» [Данилевская, 2017]. В отличие от коммерческой рекламы её основной целью является привлечение внимания к проблемам общества, воздействие на мировоззрение реципиента и, возможно, изменение его позиции, точки зрения, отношения к той или иной ситуации, на поведение людей, социальные проблемы и их решение [Мещерякова, 2012]. С дискурсивной точки зрения социальная реклама отличается от коммерческой специфичными признаками внешнего оформления и содержания, глубокой, запоминающейся, а иногда и шокирующей визуальной составляющей, иносказательностью, метафоричностью, характерной функциональной прагматической направленностью [Томская, 2000]. Эффективность общественной рекламы обусловлена закреплением в сознании реципиента в качестве его личного приобретения, знания и в дальнейшем мощным стимулом к действию [Ухова, 2014].

Несмотря на обращенный на эту проблему интерес исследователей, интерпретация императивной ситуации в дискурсе социальной рекламы на русском, немецком и английском языках не является хорошо изученной, в связи с чем представляется важным исследование данной специфики. В рамках описываемого исследования были выбраны, сопоставлены, сравнены и проанализированы более ста слоганов общественной рекламы на русском языке с привлечением немецко- и англоязычного материала с целью определения представленных в них типов императивных ситуаций. Императивная ситуация, являясь особым типом модальности, может представлять собой как непосредственно акт волеизъявления, так и его конкретное лексическое содержание, охватывая при этом два типа императивности, выделяемых по способу представления повелительности в языковом выражении [Теория функциональной ..., 1990].

\section{Интерпретация императивной ситуации на примере слоганов социальной рекламы в русском, немецком и английском языках}

Категориальная императивная семантика выражается соответствующими императивными формами [Бондарко, 2017]: Смотри на людей, а не на их инвалидность. В английском языке вместо глагола to look (смотреть) использован глагол to see (видеть), ср.: надо, необходимо увидеть человека, личность, несмотря на его особенности: See the person, not the disability (SCOPE, благотворительный фонд помощи инвалидам) ${ }^{1}$. Категориальная императивность представлена в совокупности с некатегориальной имплицитной с оттенком потенциальной возможности, ср.: у нас есть время и возможность подождать, пока вы станете нашим клиентом - Курите! Mbl вас подождём! (реклама компании по изготовлению памятников) $)^{2}$, ср: Хотите умереть? Продолжайте курить!

Имплицитная разновидность некатегориальной императивности выражается с помощью футурального индикатива (ср.: Курите, если не хотите стать родителями!) с оттенком экспрессивности, основанной на отрицательных эмоциях, страхе, своего рода реклама от противного вместе с оттенком значения возможности: будет ли такая возможность, способность, сможете ли родить, будете ли в состоянии, если продолжите курить,

1 https://aspergersandmeblog.wordpress.com/2012/08/20/see-the-person/ (дата обращения: 15.08.2020)

${ }^{2}$ https://www.sostav.ru/blogs/37775/19114/ (дата accessed: 15.08.2020). 
т.к. эта пагубная привычка может стать и часто становится причиной бесплодия. Удачно использование грамматической омонимии с омофонией: Родите ли? Курение вызыввает бесплодие (Слоган социальной кампании) ${ }^{1}$.

Некатегориальная императивность выражается вопросом о реализации возможности. В русском языке, как и в английском и немецком [Dyer, 1995; Searle, 1999; Goddard, 2002; Кириллова, 2017], формы сослагательного наклонения репрезентируют модальность возможности: может быть или возможно, ситуащия была бы другой, если бы..., вы бы уже что-то предприняли, если бы...; так не будьте безразличны, спасите! Смогли ли бы вы не обращать внимание на мои проблемы, если бы...?

Дополнительное значение необходимости выражено модальным глаголом:

- Вам было бы не так безразлично, если бы я был пандой? - англ.: Would уои care more if I was a panda? (Всемирный фонд дикой природы) ${ }^{2}$.

- Ангажировали ли меня в качестве модели, если бы я был ВИЧ-положителен? нем.: Würden Sie mich als Model buchen, wenn ich HIV-positiv wäre? (социальная кампания в поддержку ВИЧ-инфицированных в Германии).

Некатегориальная имплицитная императивность представляется в пропозитивным содержанием высказывания, ср.: лучше используйте нас для работы, а не для развлечения:

- Любая работа лучше, чем быть туристической достопримечательностью. Прекратите пожизненное заключение! - англ.: Any job is better than being a tourist attraction (Защита животных, содержащихся в неволе) ${ }^{3}$;

- Курение не просто самоубийство. Это и убийство, ср.: Прекратите убивать себя и окружающих! (Социальная реклама) ${ }^{4}$;

- Здесь могло быть ваме тело (Опасное вождение) $)^{5}$, ср.: Не дайте себе превратиться в бездыханное тело, погибнуть.

Речевая ситуация проиллюстрирована манекеном человеческого тела с рулем в руках, окруженное брызгами крови, пробившим рекламный щит и свисающим с обеих сторон. Реальная возможность при несоблюдении правил дорожного движения, необходимо соблюдать их во избежание ее реализации. Часто подобного рода посылы опираются на визуализацию, вызывающую ужас, страх, отторжение [Рюмшина, 2004].

Имплицитная некатегориальная императивность в зоне пересечения крайней периферии императивного поля с полем возможности репрезентируется ядерными средствами выражения значения возможности - модальными глаголами, значение императивности размыто, вытекает из логической цепочки, представляющей персонификацию части природы: не может сам, можете вы, защитите, это необходимо:

- англ.: The forest can't defend itself - русск.: Лес не может зашитить себя сам $(\text { Greenpeace })^{6}$; или оттягивает внимание реципиента на какую-то другую проблему, сравнивая, на первый взгляд, не подлежащее сравнению, тем самым как бы облегчая весомость диагноза.

Выстраивается цепочка: рак лечится, его можно и нужно, лечите и вылечите:

- Любовь к татуировкам, похоже, не лечится, в отличие от рака. ${ }^{7}$

Реальная модальность может быть представлена формами глагола в изъявительном наклонении с оттенком потенциальной возможности:

\footnotetext{
${ }^{1}$ https://www.sostav.ru/blogs/37775/19114/ (дата accessed: 15.08.2020).

${ }^{2} \mathrm{http} / / / \mathrm{www} .2$ social.info/sotsialnaya-reklama-wwf/ (дата обращения: 15.08.2020).

${ }^{3}$ Там же

${ }^{4}$ Там же

${ }^{5}$ Там же

${ }^{6}$ http://gazetagreencity.ru/rubrika/kultura/ekologicheskaya-socialnaya-reklama/(дата обращения: 15.08.2020).

${ }^{7}$ https://raklechitsa.ru/ (дата обращения: 15.08.2020)
} 
- Ваш ребенок - чистый лист. Кто рядом, тот и заполняет (социальная реклама) ${ }^{1}$, ср.: может заполнить, дает начало логической цепочки, приводящей к императиву: не дай быть рядом кому-то другому, не дай заполнить, заполни сам, будь всегда рядом!

Пересекаясь с полем необходимости, некатегориальная императивность вместе со значениями долженствования, необходимости представлена модальными глаголами с соответствующей семантикой:

- Ангель, которым нужна помощь (= помогите!) ${ }^{2}$;

- Каждый против каждого. Кто-то должен быть за - англ.: Everybody is against everybody. Somebody has to be for them (= будьте «за»!) (кампании против войн и насилия) ${ }^{3}$,

- нем.: Leben sollte mehr wert sein. Denn Tiere haben keinen Preis, sondern einen Wert - русск.: Жизнь необходимо больше ценить. Т.к. у животных - не цена/стоимость, а иенность (= Цените жизнь!) ${ }^{4}$

Некатегориальная императивность может быть представлена опосредованной мотивированностью действия, выраженного инфинитивной формой, волей субъекта, ср.: Пусть они производят впечатление по-другому! = Производите впечатление! Не делайте этого! Побуждение выражено с помощью инфинитива совершенного вида в русском языке, подчеркивающего результативность действия, ср. императивную форму: произведи впечатление, с оттенком возможности = можно произвести впечатление, это реально, есть другие способы, более «мирные».

- нем.: Eindruck schaffen ohne Waffen! - русск.: Произвести впечатление без оружия! (социальная реклама для подростков в Германии) ${ }^{5}$

Презентовать некатегориальную императивность могут формы инфинитива несовершенного вида с семантикой постоянности, повторяемости, многократности действия:

- Учиться у русской истории! (= надо учиться, учитесь!)

Может появляться значение отсутствия необходимости: вы - выше, лучше, достойнее этого, у вас нет в этом необходимости, нужды:

- Пацаны! Вам это не надо! (всероссийская антинаркотическая акция) ${ }^{6}$

Можно выделить значение необходимости, вынужденности или желательности:

- нем.: Wenn fliegen, dann besonders - русск.: Если летать, по по-особому (реклама авиаперевозчика Condor) ${ }^{7}$ (= должен/хочешь полететь - лети (но с нами)! если уж и приходится вам летать, возникает такая необходимость, такое желание, то следует выбирать особых, лучших авиаперевозчиков!)

Императивное значение может быть репрезентировано вопросом о реализации возможности:

- До чего мы ещё дойдём, прежде чем начнём уважать природу? (WWF)

- Как насчёт того, чтобы поделиться с теми, кто в нужде? - англ.: How about sharing with those in need? (детский благотворительный фонд) ${ }^{8}$

Для выражения семантики реальности может быть использован реальный индикатив:

- Мода требует больше жертв, чем вы думаете - англ.: Fashion claims more victims than you think ${ }^{9}$;

${ }^{1} \mathrm{http}: / /$ www.sloganbase.ru/?PageID=21\&cat=32 (дата обращения: 15.08.2020).

${ }^{2} \mathrm{http} / / /$ voxfree.narod.ru/slogan/social.html (дата обращения: 15.08.2020).

${ }^{3}$ Там же

${ }^{4}$ Там же

${ }^{5} \mathrm{https} / / / \mathrm{www}$.gruenderkueche.de/fachartikel/die-besten-10-soziale-netzwerke-und-wie-sie-sienutzen/(дата обращения: 15.08.2020)

${ }^{6} \mathrm{http}: / /$ www.sloganbase.ru/?PageID=21\&cat=32 (дата обращения: 15.08.2020).

${ }^{7} \mathrm{https} / / / \mathrm{www}$.gruenderkueche.de/fachartikel/die-besten-10-soziale-netzwerke-und-wie-sie-sienutzen/ (дата обращения: 15.08.2020)

${ }^{8}$ http://www.2social.info/sotsialnaya-reklama-wwf/ (дата обращения: 15.08.2020).

${ }^{9} \mathrm{http} / / / \mathrm{www} .2$ social.info/sotsialnaya-reklama-wwf/ (дата обращения: 15.08.2020). 
- От загрязнённой пресной воды умирает столько же людей, сколько от ядерного взрыва - англ.: Polluted river water kills as many people as a nuclear explosion (WWF) ${ }^{1}$

- Если вы не поднимите мусор, это сделают они» - англ.: If you don't pick it up they will (TBWA\Hunt Lascaris) ${ }^{2}$

В определенных речевых ситуациях или условиях с опорой на рекламные постеры с изображением зверей, которые, подобно городским стенам, запачканы граффити; шкуры которых используют для пошива модной одежды, мёртвые животные, в прямом смысле набитые отходами [Солодовникова, 2013], возникает имплицируемый императивный смысл слогана (ср.: Давайте уважать, делиться, прекратите жертвы, загрязнение!) с оттенками долженствования, отсутствия необходимости:

- Почему кто-то должен умирать, чтобы мне было тепло? Я выбираю сострадание! (= нет, не должен, нужно предотвратить это, я выбираю, выбери и ты!!) («Вита»центр защиты животных).

- Bаша подпись - наше оружие. - англ.: Your signature is our weapon (= необходимо действовать, используя мирное оружие, общество нуждается в нем) (правозащитная организация $)^{3}$.

Значение облигаторности, усиленное лексемами с оттенком актуальности: здесь и сейчас $=$ пора + инфинитив в императивной функции (=бросай сейчас!):

- Самое время и место, чтобы бросить курить! ${ }^{4}$

Форма изъявительного наклонения прошедшего времени в несобственной функции репрезентирует действие как уже свершившееся, реализованное с оттенком реальной модальности в отличие от форм императива, имеющих футуральную отнесенность с оттенком потенциальности:

- Взял и бросил! (= возьми и брось) (День отказа от курения) $)^{5}$

Инфинитив может репрезентировать значение возможности:

- Читать "Спорт-Экспресс» не значит, увлекаться спортом (=можно читать, но лучше занимайся) ${ }^{6}$.

Формы индикатива могут выражать значение необходимости - необходимость избавить себя и окружающих от вредных воздействий:

- Вдыхая - убиваешь себя, выдыххая - других (=и то, и другое - плохо, не вреди ни себе, ни другим, бросай!) ${ }^{7}$

- Этот мир лучше без наркотиков. Когда в жизни есть цель, наркотики не нуж$H b l$ (= живи без них, иди к своей цели $)^{8}$

- Кто не рискует - тот не пьет шампанское. Кто пьет за рулем - рискует потерять все (ГИБДД) (= не пей, нельзя это допустить, иначе потеряешь всё) ${ }^{9}$

- Вам лучше не смотреть на тех, кто не смотрел на знаки ограничения скорости. (ГИБДД) (= от неприятного пугающего зрелища: не нужно Вам это видеть, это ужасает, не нужно нарушать правила, соблюдай их $)^{10}$ лен, осторожен) ${ }^{1}$

- Внимательность на дорогах - еще никому не мешала (ГИБДД) (= будь внимате-

1 http://gazetagreencity.ru/rubrika/kultura/ekologicheskaya-socialnaya-reklama/ (дата обращения: 15.08.2020).

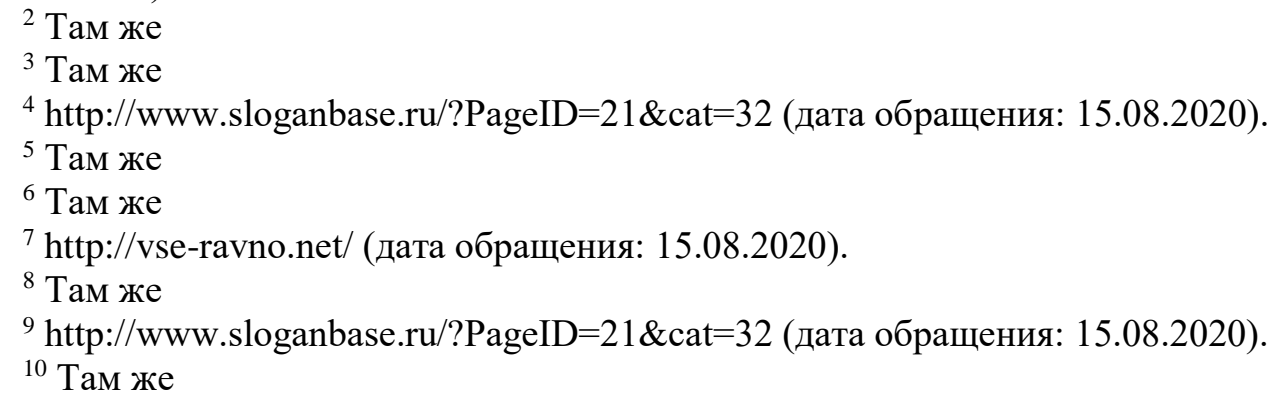


- Дворы и игровые площадки - для детей, а не для ваших железных коней (ГИБДД) ${ }^{2}$ (= не паркуй свой автомобиль с помехой для окружающих)

- нем.: Einer rast, zwei sterben - русск.: Один мчится, двое умирают ${ }^{3}$ = если ты превышаешь скорость, можешь погибнуть не только ты, но и другой водитель, необходимо соблюдать скоростной режим, соблюдай, не превышай скорость) (безопасность движения в Германии)

- Когда ты оставляешь свет включённым, тыл не единственный, кто плаmum $(\mathrm{WWF})^{4}$ (= необходимость беречь ресурсы, облигаторность).

\section{Заключение}

Таким образом, как прямая, так и косвенная императивность имеют своей целью побуждение реципиента к какому-либо действию или решению. Для дискурса общественной рекламы на русском, а также в иноязычных примерах (на немецком и английском языках) преимущественно характерно наличие косвенного императива, который в отличие от прямого, чаще встречающегося в коммерческой рекламе и побуждающего к мгновенному возникновению желания, принятию решения, быстрому действию, заставляет реципиента размышлять, представляя предпосылки для самостоятельных выводов, оценки, построения ассоциативного ряда, позволяет ему занимать ту или иную позицию или менять свою, существовавшую прежде точку зрения.

В проанализированных примерах на разных языках выявлены общность или сходство внутреннего содержания слогана, позволяющие сделать выводы об общности основных человеческих ценностей, таких как мир, жизнь, здоровье, окружающая природа, сходстве общественных целей и задач представителей разных культур, средства выражения языков которых и явились материалом исследования. Бо́льшие различия были выявлены в оттенках значений при выражении общей смысловой основы, что обусловлено разными языковыми средствами, характерными для того или иного языка (например, уникальные для русского языка формы изъявительного наклонения прошедшего времени в функции императива, формы герундия - для английского), разными реалиями того или иного социума.

\section{Список литературы}

1. Бондарко А.В. 2017. Глагольные категории в системе функциональной грамматики. Под ред. Т.В. Рождественской, М.Д. Воейковой. М., Издательский дом Языки славянских культур, 336 с.

2. Данилевская Н.В. 2017. Социальная реклама как регулятор духовно-нравственного состояния общества: культурологический аспект. Коммуникативные исследования, 3 (13): 18-29. DOI: $10.25513 / 2413-6182.2017 .3 .18-29$.

3. Кириллова Ю.Н. 2017. Лингвостилистические особенности текста социальной рекламы (на материале немецкого языка). Изв. Сарат. ун-та. Нов. сер. Сер. Филология. Журналистика, 17 (3): 265-272. DOI: 10.18500/1817-7115- 2017-17-3-265-272.

4. Мещерякова Н.В. 2012. Стилистические и прагмалингвистические особенности рекламных текстов социальной направленности. М., $241 \mathrm{c}$.

5. Рюмшина Л.И. 2004. Манипулятивные приёмы в рекламе. М., Март, 240 с.

6. Солодовникова А.Н. 2013. Современная социальная реклама: способы воздействия на адресата. Дис. ... канд. филол. наук. Саратов, 197 с.

\footnotetext{
${ }^{1} \mathrm{http}: / /$ www.sloganbase.ru/?PageID=21\&cat=32 (дата обращения: 15.08 .2020 ).

${ }^{2}$ Там же

${ }^{3} \mathrm{https}: / / \mathrm{www}$.gruenderkueche.de/fachartikel/die-besten-10-soziale-netzwerke-und-wie-sie-sienutzen/ (дата обращения: 15.08.2020).

${ }^{4}$ http://www.2social.info/sotsialnaya-reklama-wwf/ (дата обращения: 15.08.2020).
} 
7. Теория функциональной грамматики: Темпоральность. Модальность. 1990. Под ред. А.В. Бондарко. Л., Наука, 263 с.

8. Томская М.В. 2000. Оценочность в социальном рекламном дискурсе. М., 200 с.

9. Ухова Л. 2014. Эффективность рекламного текста. М., Директ-Медиа, 190 с.

10. Goddard A. 2002. The Language of Advertising. Routledge, $144 \mathrm{p}$.

11. Dyer G. 1995. Advertising as Communication. London, 143p.

Books, 187 p.

12. Searle J.R. 1999. Mind, Language and Society. Philosophy in the Real World. N.Y., Basic

\section{References}

1. Bondarko A.V. 2017. Glagol'nye kategorii v sisteme funktsional'noy grammatiki [Verb categories in the functional grammar system]. Eds. T.V. Rozhdestvenskay, M.D. Voeykova. M., Publ. Izdatel'skiy dom Yazyki slavyanskikh kul'tur, $336 \mathrm{p}$.

2. Danilevskaya N.V. 2017. Sotsial'naya reklama kak regulyator dukhovno-nravstvennogo sostoyaniya obshchestva: kul'turologicheskiy aspekt [Social advertising as a regulator of the spiritual and moral state of society: a cultural aspect]. Communication Studies, 3 (13): 18-29. DOI: 10.25513/24136182.2017.3.18-29.

3. Kirillova Yu. N. 2017. Lingvostilisticheskie osobennosti teksta sotsial'noy reklamy (na materiale nemetskogo yazyka) [Linguistic and stylistic features of the text of social advertising (based on the material of the German language)]. Izvestiya of Saratov University. New Series. Series: Philology. Journalism, 17 (3): 265-272. DOI: 10.18500/1817-7115- 2017-17-3-265-272 (in Russian)

4. Meshcheryakova N.V. 2012. Stilisticheskie i pragmalingvisticheskie osobennosti reklamnykh tekstov sotsial'noy napravlennosti [Stylistic and pragmalinguistic features of social advertising texts]. M., $241 \mathrm{p}$.

5. Ryumshina L.I. 2004. Manipulyativnye priemy v reklame [Manipulative Techniques in Advertising]. M., Publ. Mart, 240 p.

6. Solodovnikova A.N. 2013. Sovremennaya sotsial'naya reklama: sposoby vozdeystviya na adresata [Modern social advertising: ways of influencing the addressee]. Dis. ... Cand. philol. sciences. Saratov, $197 \mathrm{p}$.

7. Teoriya funktsional'noy grammatiki: Temporal'nost'. Modal'nost' [Theory of functional grammar: Temporality. Modality]. 1990. Ed. A.V. Bondarko. L., Publ. Nauka, 263 p.

8. Tomskaya M.V. 2000. Otsenochnost' v sotsial'nom reklamnom diskurse [Evaluation in Social Advertising Discourse]. M., 200 p.

9. Ukhova L. 2014. Effektivnost' reklamnogo teksta [The effectiveness of advertising text]. M., Publ. Direkt-Media, 190 p.

10. Goddard A. 2002. The Language of Advertising. Routledge, 144 p.

11. Dyer G. 1995. Advertising as Communication. London, 143p.

12. Searle J.R. 1999. Mind, Language and Society. Philosophy in the Real World. N.Y., BasicBooks, 175 p.

\section{ИНФОРМАЦИЯ ОБ АВТОРЕ}

Шлык Елена Владимировна, кандидат филологических наук, доцент кафедры иностранных языков Брянского государственного университета им. ак. И.Г. Петровского, г. Брянск, Россия

\section{INFORMATION ABOUT THE AUTHOR}

Elena V. Shlyk, Candidate of Philology, Associate Professor of the Department of Foreign Languages, Bryansk State University named after ac. I.G. Petrovsky, Bryansk, Russia 